\title{
Thyroid Dysfunction In Pregnancy And Its Maternal Outcome
}

\author{
${ }^{1}$ Dr.Thanuja.P.M, ${ }^{2}$ Dr. Rajgopal.K,${ }^{3}$ Dr.Sadiqunnisa \\ 1,2,3 (Department of Obstetrics and Gynaecology, Yenepoya Medical College, India)
}

\begin{abstract}
Thyroid disorders are among the common endocrine problems in pregnant women. Thyroid dysfunction may be overlooked in pregnancy because of the nonspecific symptoms and hypermetabolic state of normal pregnancy. Thyroid dysfunction has varied impact on pregnancy outcome. The risk of miscarriage is increased in autoimmune thyroid disease. Severe maternal hypothyroidism can result in irreversible neurological deficit in the offspring. Graves' disease can lead to pregnancy loss as well as fetal thyroid dysfunction.Measurement of serum TSH is the most practical, simple and economic screening test for thyroid dysfunction.
\end{abstract}

\section{INTRODUCTION}

Thyroid disorders are among the common endocrine disorders in pregnant women. Thyroid dysfunction may be overlooked in pregnancy because of the nonspecific symptoms and hypermetabolic state of normal pregnancy.

Thyroid dysfunction has varied impact on pregnancy outcome. The risk of miscarriage is increased in autoimmune thyroid disease. Severe maternal hypothyroidism can result in irreversible neurological deficit in the offspring. Graves' disease can lead to pregnancy loss as well as fetal thyroid dysfunction.

There is few data from India about the prevalence of thyroid dysfunction in pregnancy. This study was conducted in Yenepoya Medical College Hospital in Mangalore. This is a prospective study which includes screening of 300 pregnant patients attending the OPD of the OBG department of Yenepoya medical college and included in the study after fulfilling inclusion and exclusion criteria.

This study aims to know the occurrence of thyroid dysfunction in pregnancy and its impact on obstetric outcome in Dakshin Kannada district in Mangalore, India.

\section{Objectives Of The Study}

1) To estimate the occurrence of thyroid disease in pregnancy

2) To evaluate obstetric and perinatal outcomes in patients with thyroid dysfunction.

\subsection{Source of data}

\section{Methodology}

Patients within the inclusion criteria attending the OPD of the OBG department of Yenepoya medical college during the period of December 2011- November 2013

\subsection{Study design: Prospective study}

3.3 Inclusion criteria

Among pregnant women attending OBG OPD of Yenepoya Hospital, 300 women with singleton pregnancy irrespective of the period of gestation are selected by random sampling.

\subsection{Exclusion criteria}

1. Documented history of thyroid dysfunction

2. Multiple pregnancies

3. Gestational trophoblastic diseases

4. Women on treatment for thyroid dysfunction.

5. Any medical co-morbidities.

6. Bad Obstetric history with known cause.

300 pregnant women irrespective of the period of gestation are selected by random sampling from the patients attending the OPD of the OBG department of Yenepoya medical college and included in the study after fulfilling inclusion and exclusion criteria.

1) Informed written consent to be taken after explaining the background of study and benefits and voluntary nature of participation. 
2) A thorough general physical examination and systemic examination will be done before being included in the study and per speculum and per vaginal examination is done when indicated.

3) Blood sample is taken and sent for TSH. Patients with abnormal TSH values are further followed up with free T3 and free T4 values and the obstetric and neonatal outcomes.

The following outcome variables in relation to thyroid disorders studied:

$\square$ Preeclampsia.

$\square$ Abruptio placenta.

Preterm delivery.

Abortion

Preeclampsia was defined as persistently elevated blood pressure (systolic $>140 \mathrm{mmHg}$ and diastolic pressure $>90 \mathrm{mmHg}$ on more than 2 occasions) with protenuria. Abruption placenta was defined as a form of antepartum haemorrhage where the bleeding occurs due to premature separation of normally situated placenta. Preterm delivery was defined as delivery before 37 completed weeks of gestation. Abortion was defined as spontaneous termination of pregnancy before the period of viability .

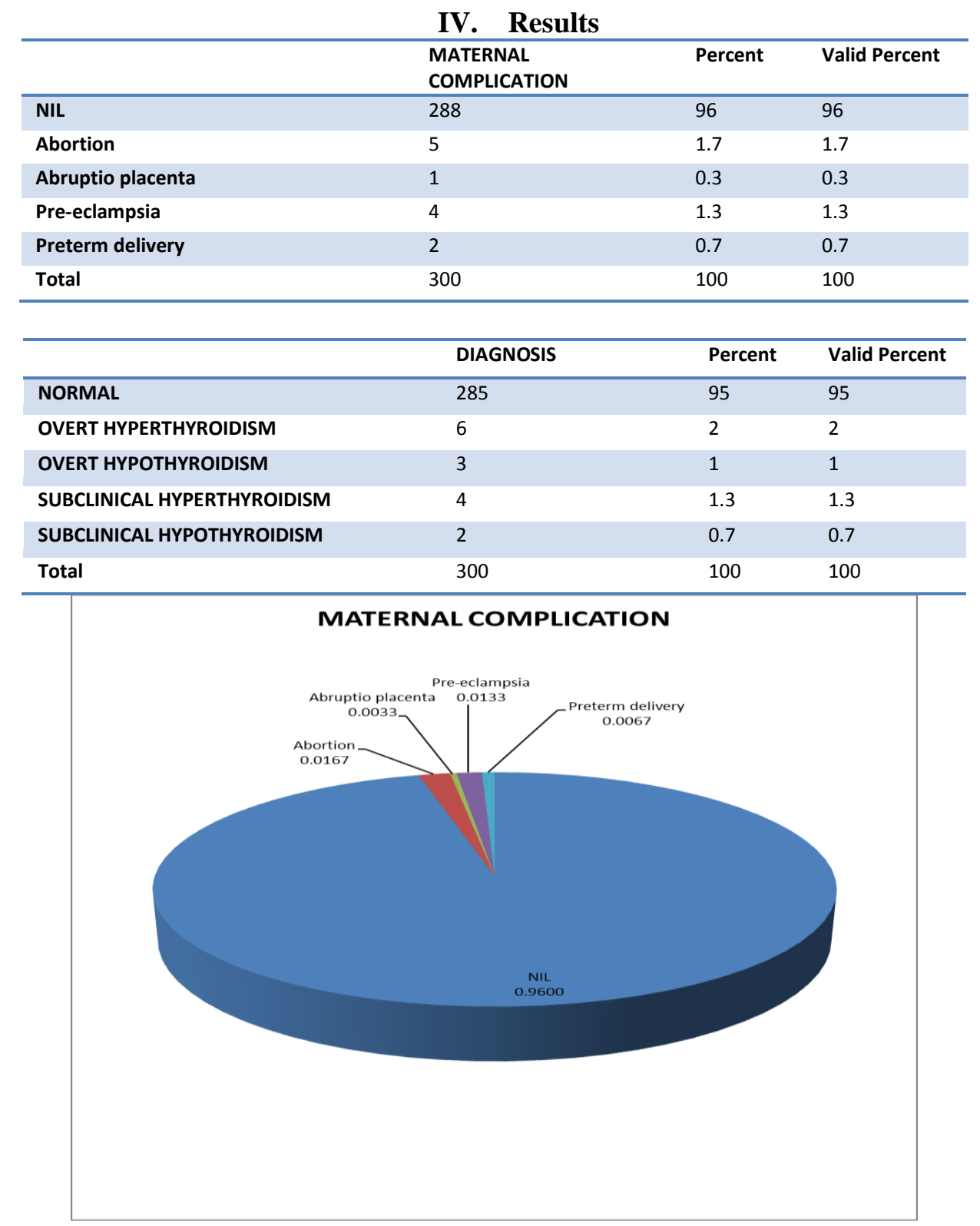




\begin{tabular}{|c|c|c|c|c|c|c|c|c|}
\hline \multicolumn{9}{|c|}{ MATERNAL COMPLICATION * DIAGNOSIS Crosstabulation } \\
\hline & & & \multicolumn{5}{|c|}{ DIAGNOSIS } & \multirow{2}{*}{ Total } \\
\hline & & & $\begin{array}{l}\text { NORMA } \\
\mathrm{L}\end{array}$ & $\begin{array}{l}\text { OVER } \\
\text { T } \\
\text { HYPE } \\
\text { RTHY } \\
\text { ROIDI } \\
\text { SM }\end{array}$ & $\begin{array}{l}\text { OVERT } \\
\text { HYPOT } \\
\text { HYROID } \\
\text { ISM }\end{array}$ & $\begin{array}{l}\text { SUBCL } \\
\text { INICAL } \\
\text { HYPE } \\
\text { RTHY } \\
\text { ROIDI } \\
\text { SM }\end{array}$ & $\begin{array}{l}\text { SUBCLI } \\
\text { NICAL } \\
\text { HYPOT } \\
\text { HYROID } \\
\text { ISM }\end{array}$ & \\
\hline \multirow{15}{*}{$\begin{array}{l}\text { MATER } \\
\text { NAL } \\
\text { COMPLI } \\
\text { CATION }\end{array}$} & & Count & 285 & 0 & 0 & 2 & 1 & 288 \\
\hline & & $\begin{array}{l}\% \\
\text { MATERNAL } \\
\text { COMPLICATION }\end{array}$ & $99.0 \%$ & $0.0 \%$ & $0.0 \%$ & $0.7 \%$ & $0.3 \%$ & $100.0 \%$ \\
\hline & & $\begin{array}{l}\% \\
\text { DIAGNOSIS }\end{array}$ & $100.0 \%$ & $0.0 \%$ & $0.0 \%$ & $50.0 \%$ & $50.0 \%$ & $96.0 \%$ \\
\hline & \multirow[t]{3}{*}{ Abortion } & Count & 0 & 3 & 2 & 0 & 0 & 5 \\
\hline & & $\begin{array}{l}\text { \% within } \\
\text { MATERNAL } \\
\text { COMPLICATION }\end{array}$ & $0.0 \%$ & $60.0 \%$ & $40.0 \%$ & $0.0 \%$ & $0.0 \%$ & $100.0 \%$ \\
\hline & & $\begin{array}{l}\% \\
\text { DIAGNOSIS }\end{array}$ & $0.0 \%$ & $50.0 \%$ & $66.7 \%$ & $0.0 \%$ & $0.0 \%$ & $1.7 \%$ \\
\hline & \multirow{3}{*}{$\begin{array}{l}\text { Abruptio } \\
\text { placenta }\end{array}$} & Count & 0 & 0 & 1 & 0 & 0 & 1 \\
\hline & & $\begin{array}{l}\text { \% } \\
\text { MATERNAL } \\
\text { COMPLICATION }\end{array}$ & $0.0 \%$ & $0.0 \%$ & $100.0 \%$ & $0.0 \%$ & $0.0 \%$ & $100.0 \%$ \\
\hline & & $\begin{array}{l}\% \\
\text { DIAGNOSIS }\end{array}$ & $0.0 \%$ & $0.0 \%$ & $33.3 \%$ & $0.0 \%$ & $0.0 \%$ & $0.3 \%$ \\
\hline & \multirow[t]{3}{*}{ Pre-eclampsia } & Count & 0 & 2 & 0 & 2 & 0 & 4 \\
\hline & & $\begin{array}{l}\% \\
\text { MATERNAL } \\
\text { COMPLICATION }\end{array}$ & $0.0 \%$ & $50.0 \%$ & $0.0 \%$ & $50.0 \%$ & $0.0 \%$ & $100.0 \%$ \\
\hline & & $\begin{array}{l}\% \\
\text { DIAGNOSIS }\end{array}$ & $0.0 \%$ & $33.3 \%$ & $0.0 \%$ & $50.0 \%$ & $0.0 \%$ & $1.3 \%$ \\
\hline & \multirow[t]{3}{*}{ Preterm delivery } & Count & 0 & 1 & 0 & 0 & 1 & 2 \\
\hline & & $\begin{array}{l}\text { \% within } \\
\text { MATERNAL } \\
\text { COMPLICATION }\end{array}$ & $0.0 \%$ & $50.0 \%$ & $0.0 \%$ & $0.0 \%$ & $50.0 \%$ & $100.0 \%$ \\
\hline & & $\begin{array}{l}\% \\
\text { DIAGNOSIS }\end{array}$ & $0.0 \%$ & $16.7 \%$ & $0.0 \%$ & $0.0 \%$ & $50.0 \%$ & $0.7 \%$ \\
\hline \multirow{3}{*}{\multicolumn{2}{|c|}{ Total }} & Count & 285 & 6 & 3 & 4 & 2 & 300 \\
\hline & & $\begin{array}{l}\text { \% } \\
\text { MATERNAL } \\
\text { COMPLICATION }\end{array}$ & $95.0 \%$ & $2.0 \%$ & $1.0 \%$ & $1.3 \%$ & $0.7 \%$ & $100.0 \%$ \\
\hline & & $\begin{array}{l}\% \\
\text { DIAGNOSIS }\end{array}$ & $100.0 \%$ & $\begin{array}{l}100.0 \\
\%\end{array}$ & $100.0 \%$ & $\begin{array}{l}100.0 \\
\%\end{array}$ & $100.0 \%$ & $100.0 \%$ \\
\hline
\end{tabular}

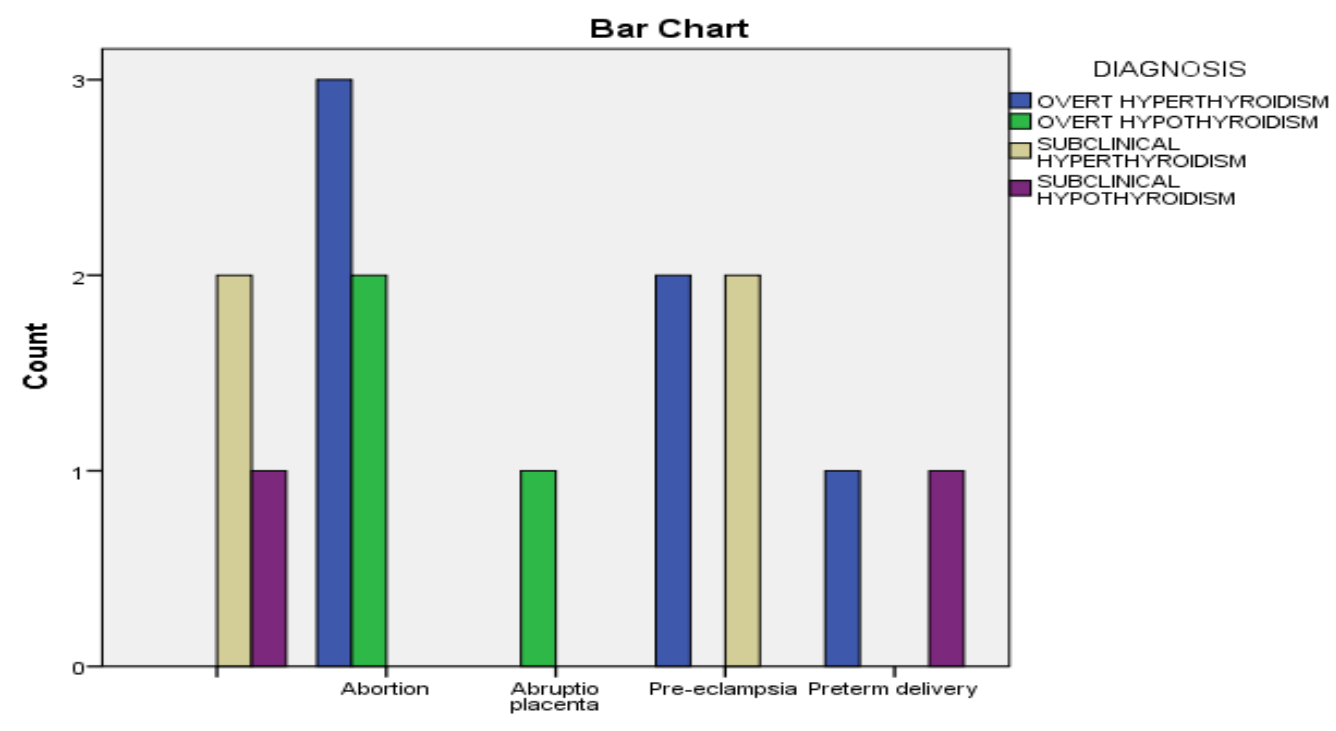

MATERNAL COMPLICATION 


\section{Discussion}

The present study was done in Yenepoya Medical College Hospital, Mangalore. A total of 300 patients were screened for thyroid disorders in this study.

It was a prospective study. The main aim of the study was to know the occurrence of

thyroid disorders in pregnancy and maternal outcome.

Our study was done in 300 pregnant patients irrespective of the period of gestation as compared to the study of Sahu $\mathrm{M}$ et $\mathrm{al}^{1}$, who studied 633 women in second trimester.

The occurrence of thyroid disorders in our study was 5\%. Our findings are not consistent with the reports from the study of Sahu M et al ${ }^{1}$, who studied 633 women in second trimester. In their study the prevalence of thyroid disorders was $12.7 \%$, which is not comparable to our study.

The occurrence of subclinical hypothyroidism in our study was $0.7 \%$. In the study of Sahu MT et $\mathrm{al}^{1}$ the prevalence was $6.47 \%$, which is not comparable to our study. In a study done by Casey BM et $\mathrm{al}^{2}$, the prevalence was $23 \%$ which is very high and not consistent with our study.

The occurrence of overt hypothyroidism in our study was $1 \%$, which is not consistent with a study done by Sahu MT et $\mathrm{al}^{1}$, in which the prevalence is $4.58 \%$.

The occurrence of subclinical and overt hyperthyroidism in our study was $1.3 \%$ \& $2 \%$ respectively. In a study done by Sahu MT et $\mathrm{al}^{1}$, the prevalence was $0.9 \% \& 0.7 \%$ for subclinical and overt hyperthyroidism . The prevalence of sublinical hyperthyroidism is comparable with other studies.

In a study done by Tuija mannisto et $\mathrm{al}^{3}$, the prevalence was $3.5 \% \& 1.3 \%$ for subclinical and overt hyperthyroidism .

The prevalence of Subclinical and Overt Hyperthyroidism was 0.5 and $0.4 \%$ respectively in a study done by Stagnaro Green ${ }^{4}$

In our study of 300 patients, 2 patients $(0.7 \%)$ had subclinical hypothyroidism. Of these, the maternal complications included 1 case of abortion (50\%) \& 1 case of low birth weight (50\%). In a study done by Leung et al the incidence complications were PE (15\%), PTD (9\%), LBW (9\%) in cases of subclinical hypothyroidism, which is higher than our study. In a study done by Sahu MT et $\mathrm{al}^{1}$, the complications like PE $(9.8 \%)$, PTD (10.3\%), IUGR (2.4\%), SB (2.5\%) were seen in cases of subclinical hypothyroidism.

In our study, the occurrence of overt hypothyroidism was $3(1 \%)$. Of these, the maternal complications included 2 abortions $(66.7 \%) \& 1$ case of abruptio placenta (33.4\%).. In a study done by Sahu MT et $\mathrm{al}^{1}$, the complications like PE (20.7\%), PTD (4.7\%), IUGR (13.8\%), SB (2.9\%) were seen in cases of overt hypothyroidism. In a study done by Leung et $\mathrm{al}^{5}$, the incidence of complications were PE(22\%), LBW (22\%), $\mathrm{SB}(4 \%)$ in cases of overt hypothyroidism. In a study done by Abolovich et $\mathrm{al}^{2}$ the complications like AP (19\%), LBW $(6 \%), \mathrm{SB}(3 \%)$ were seen in cases of overt hypothyroidism. There were no cases of abruptio placenta in these studies whereas our study showed 1 case of abruption.

In our study, the occurrence of subclinical hyperthyroidism was $4(1.3 \%)$. Of these, the maternal complications included 2 cases of pre-eclampsia (50\%) and fetal complication of IUGR in 1 patient (25\%). The occurrence of overt hyperthyroidism was $6(2 \%)$. The maternal complications included 3 abortions (50\%), 2 cases of pre-eclampsia (33.4\%) \& 1 case of pre-term delivery (16.67\%). In a study done by Robert negro et al ${ }^{6}$ the hyperthyroidism in low risk group was associated with complications like gestational $\mathrm{HTN}(16.7 \%)$, PE $(0 \%)$, PTD(16.7\%), AB $(14.3 \%), \mathrm{SB}(0 \%)$. In a study done by Tuija Mannisto et $\mathrm{al}^{3}$, the subclinical hyperthyroidism was associated with complications like PE $(3.5 \%), \mathrm{AP}(1 \%)$. In a study done by Miller et $\mathrm{al}^{7}$, hyperthyroidism was associated with complications like PE(4.7\%), LBW (2.3\%) . In a study done by Kriplani A et $\mathrm{al}^{8}$ hyperthyroidism was associated with complications like PE $(22 \%), \mathrm{PTD}(25 \%)$ and no perinatal death occurred in this study. The incidence of complications varied in different studies

To accept the weakness of our study, the sample size was only 300 . The study has to be done in a bigger population. Also, these women were not screened for thyroid antibodies. At present there is no available recommendations for detection or screening of thyroid dysfunction among Indian pregnant women. Recent consensus guidelines do not advocate universal thyroid function screening during pregnancy, but recommend testing for high risk women with personal history of thyroid or other autoimmune disorders or with a family history of thyroid disorders or symptoms of thyroid dysfunction.

\section{CONCLUSION}

OUR STUDY SHOWS LOW OCCURRENCE OF THYROID DYSFUNCTION, BUT 12 OUT OF THE 15 CASES OF THYROID DYSFUNCTION WERE ASSOCIATED WITH MATERNAL COMPLICATIONS

Based on the complications seen in the present study we therefore suggest a decreased threshold for screening and detection of thyroid dysfunction among Indian pregnant women attending routine antenatal clinic and recommend increased awareness of associated maternal and fetal complications. 


\section{REFERENCES}

[1]. Sahu MT et al. Overt and subclinical thyroid dysfunction among Indian pregnant women and its effect on maternal and fetal outcome. Archives of gynecology and obstetrics. 2010;281(2):215-220.

[2]. Vaidya B, Antony S. Bilousm et al. Detection of Thyroid dysfunction in early pregnancy. Universal screening or high risk targeted case finding? J Clin Endocronol. Metab 2007; 92(1): 203-207.

[3]. Tuija Mannisto , Marja Vaarasmaki et al. Thyroid dysfunction and maternal morbidity.J Clin Endocrinol Metab,2010;95(3):10841094

[4]. Stagnaro GA et al. Overt Hyperthyroidism and Hypothyroidism during pregnancy. Clin Obstet Gynaecol 2011; 54(3):478-82.

[5]. Leung AS, Millar L.K, Kooning PP, Montorom, Mestman J. Perinatal outcomes in hypothyroid pregnancies Obstet Gynecol 1993;81(3):349-353.

[6]. Robert Negro, Alan Schwartz et al. Detection and treatment of thyroid in pregnancy. J Clin Endocrinol Metab,2010;95(4):16991707.

[7]. Kriplani A, Buckshee K et al Maternal and perinatal outcome in thyrotoxicosis complicating pregnancy. Eur J Obstet Gynecol Reprod Biol. 1994;54(3):159-63

[8]. Millar LK, Wing DA, Low birth weight and preeclampsia in pregnancies complicated by hyperthyroidism.Obstet Gynecol. 1994;84(6):946-9. 